\title{
ADENOMA OF PANCREATIC ISLET CELLS WITH HYPOGLYCEMIA AND HYPERINSULINISM
}

\author{
Report of a Case with Studies on Blood Sugar and Metabolism before and \\ after Operative Removal of Tumor
}

By S. H. Liv, H. H. Loucks, S. K. Chou and K. C. Chen

(From the Departments of Medicine and Surgery, Peiping Union Medical College, Peiping, China)

(Received for publication December 16, 1935)

Shortly after Banting and Best's discovery of insulin (1), Harris (10) in 1924, on the basis of cases of hypoglycemia with symptoms similar to those of insulin shock and relievable by feeding, postulated the occurrence of spontaneous " hyperinsulinism" as opposed to the "hypoinsulinism" of diabetes. The first verification of this hypothesis appeared in 1927 in a report by Wilder, Allan, Power and Robertson (26) of a case of intractable hypoglycemia. The patient, on exploration, showed carcinoma of the islet tissue of the pancreas with metastasis to the liver. Insulin was demonstrated in the hepatic metastases. Two years later Howland, Campbell, Maltby and Robinson (12) reported the first case of pancreatic islet adenoma which was diagnosed preoperatively, identified at operation and excised with favorable result.

In the past few years the literature on hyperinsulinism has grown tremendously. A review by Whipple and Frantz (25) of all the published cases of hyperinsulinism and islet tumor has appeared very recently. According to their analysis of the 157 cases reported, 75 cases of hypoglycemia were ascribed to hyperinsulinism without verification at operation or autopsy. Of the 82 remaining cases in which the pancreas was examined, normal tissue was recorded in 13 instances, hypertrophy of the islands in 4 instances and chronic inflammatory change in 3 , leaving 62 instances in which a tumor of the pancreatic islands was found. Analyzing further the 62 cases of tumor, exactly 50 per cent were incidental necropsy findings without recorded hypoglycemia. The group of 31 cases of tumor associated with hypoglycemia consists of 10 discovered at autopsy and 21 at operation. Among the last 21 cases, 4 were instances of carcinoma in which death occurred shortly after operation in 2 instances.
There remain 17 patients with adenoma, the excision of which led to eventual recovery. Thus in spite of frequent reports of hypoglycemia and hyperinsulinism, adenoma of the pancreatic islets, verified at operation with favorable outcome after extirpation of the tumor is a relatively rare condition. We are reporting the history of such a case together with the results of blood sugar and metabolism studies and biological assay of the tumor for insulin.

\section{CASE REPORT}

A Chinese man, M. T. L., aged 49 years, a mine foreman, was admitted to the Hospital on November 23, 1934, for attacks of unconsciousness and convulsions. He apparently had been well until April 1930 when, on one occasion, his consciousness became clouded after he had been awakened suddenly at night. His normal mental state returned in 3 hours after he had been given food. A similar attack occurred in September of the same year after the omission of breakfast. On that occasion he showed, in addition, haphazard movements of his limbs and profuse perspiration. Feeding again brought him out of coma. In March 1931 a strenuous journey by bicycle was followed by weakness and stiffness of the legs and collapse from which he recovered promptly after taking food. He once went to sleep without supper, and at 4 o'clock the next morning became semicomatose and then delirious, moving his arms violently, running out of his room and shouting loudly. Thereafter the attacks became more frequent, recurring approximately once every one to three months. Involuntary urination occurred during one of the attacks.

In February 1934 generalized clonic convulsions were first noticed, accompanied by coma. Subsequently similar seizures recurred almost every night, usually between 2 and 4 a.m. According to the description given by his wife, the onset of the seizures was marked by a cessation of the snoring which occurred regularly during sleep and the opening of his eyes accompanied by staring and grimacing. Twitching movements first involved the lower limbs and then the upper. In the beginning the movements were slight and then more violent. Occasionally the tongue was bitten. Each series of con- 
vulsions usually lasted a few minutes and would be followed by an interval of relative quietness during which the patient could be induced to swallow some carbohydrate foods which his wife had learned to feed him in order to abolish the attacks.

During the intervals between the attacks the patient apparently was normal except for an impaired memory of recent events. He grew very fat during the two years prior to admission, his appetite being enormously increased. There was no loss of libido or potency. $\mathrm{He}$ had abandoned his work in 1932.

In the past history there was a record of smallpox at the age of 12 , dysentery at 37 , urethral discharge at 38 , and an acute febrile illness of unknown nature at 42 .

Physical examination. Between attacks the patient appeared perfectly comfortable. Temperature $37.4^{\circ} \mathrm{C}$., pulse 80 , blood pressure $104 / 70$, height $172 \mathrm{~cm}$., weight $96.7 \mathrm{kgm}$. The patient was well developed and markedly obese, with fat distributed generally without special predilection for given regions. Distribution of hair was normal except for a tendency toward the feminine type in the pubic region. The ocular fundi showed a slight degree of perivasculitis of the retinal vessels; visual fields normal. Thyroid gland was not enlarged. Lungs were normal. Heart was not enlarged, and the radial arteries were not thickened. Masses or individual organs could not be palpated within the abdomen. External genitalia were normal; prostate gland not enlarged. Neurological examination revealed nothing of significance. Dr. H. I. Chu, who saw the patient first in the Outpatient Clinic, suggested the diagnosis of hypoglycemic syndrome.

Laboratory data. Urinalysis gave normal findings and stools proved negative for ova or parasites. The red blood count was 5.9 million; hemoglobin, 15.3 grams; and white blood cells, 12,100 with 67 per cent neutrophiles. The blood sugar during the postabsorptive period as determined on many occasions was between 40 and $50 \mathrm{mgm}$. per cent. Icterus index was 6 . A bromsulphalein test revealed no retention of the dye after 30 minutes. Roentgenologic examination of the skull showed a normal sella turcica. The basal metabolic rate was 1,977 calories per diem or +3.0 per cent. Blood Wassermann reaction was negative.

The ordinary three-meal diet was not adequate to prevent convulsive seizures which usually came between 4 and 5 a.m. The patient therefore was given a diet containing 3,000 calories with 473 grams carbohydrates divided into 5 equal portions served at 8 a.m., 12 noon, 5 p.m., 10 p.m. and 3 a.m. This regimen kept him free from symptoms for a few days, but after that mild attacks re-appeared before the 3 a.m. and 8 a.m. feedings, and the diet had to be increased to 3,500 calories with 600 grams carbohydrates.

During the interval between admission and operation various studies on blood sugar and metabolism were made, which are described later.

Operation. On January 2, 1935, with the patient under ether anesthesia a laparotomy was performed (H. H. L.).
The abdomen was opened through a left rectus incision extending from the xiphoid process to a point about $3 \mathrm{~cm}$. below the umbilicus. The subcutaneous and omental fat was large in quantity and a portion of the greater omentum was excised in order to facilitate exposure. The usual exploration revealed the fact that the liver was small with smooth surfaces and a thin, almost knife-like edge. The gallbladder, stomach, duodenum, small intestine, appendix and colon all appeared normal. The spleen was small. It was difficult to palpate the kidneys on account of excessive perirenal fat.

A duodenal tube was passed to deflate the stomach, and the pancreas was approached through the gastrocolic omentum. Along the upper margin of the right half of the body of the pancreas at approximately the point of junction of the head and body lay a tumor $2.5 \mathrm{~cm}$. in diameter which was somewhat firmer in consistency than the rest of the gland. It was dark red in color and was elevated slightly above the surface of the gland. It appeared to be contained within a thin capsule and was enucleated easily from its bed in the pancreas. Numerous large veins ran between the capsule and the substance of the gland and hemostasis presented some difficulty, ligatures and the coagulating current both being employed. An iodoform gauze drain was packed lightly into the denuded area, and two cigarette drains were placed down to the level of the pancreas. The gastrocolic omentum was closed by interrupted sutures of fine silk. The abdominal wall was closed in layers around the drains, the closure being reinforced by three stay sutures of silver wire.

Postoperative course. For some hours prior to and during the operation, as well as for some hours subsequently, the patient was given a 5 per cent solution of glucose in normal saline by means of a continuous intravenous drip (40 drops per minute). The blood sugar at 9 a.m. (before operation) was 59, and at 1 p.m. (shortly after operation) it was 158; later in the day it rose to $264 \mathrm{mgm}$. per cent and sugar appeared in the urine. Temperature $39.3^{\circ}$ C.; pulse 130 . Glucose by intravenous drip was discontinued and $400 \mathrm{cc}$. of citrated blood were given.

On the next day the temperature went higher $\left(40.4^{\circ}\right.$ C.), and the respirations increased to 34 per minute. Aside from slight cough and a few râles heard at the bases of both lungs, there was nothing to indicate a pulmonary complication. A moderate bloody discharge drained from the operative wound. One cigarette drain was removed. The white blood cell count was 8,850 . The blood sugar was maintained between 175 and 245 mgm. per cent, and the urinary sugar totaled 4 grams in 24 hours. Insulin was started, and given in doses of ten units three times a day.

On the third day the fever began to subside, the general condition improving. The blood sugar was 238 to $300 \mathrm{mgm}$. per cent; the urine sugar 17 grams. The iodoform gauze drain was removed.

On the fourth day the patient was well enough to take a high caloric diet. The blood sugar was $276 \mathrm{mgm}$. 
per cent and the urinary sugar totaled 22 grams. On the fifth day the temperature became normal. The last drain was removed and some serosanguineous discharge came from the wound. The hyperglycemia and glycosuria tended to diminish. Insulin was discontinued on the 7 th day, and the blood sugar became normal and the urine sugar-free on the 9th day, before a calculated diabetic diet was started. From then on convalescence was uncomplicated, the wound closing gradually and the discharge becoming less in amount. The patient was up and about three weeks after the operation and did not experience any of the symptoms which had been present previously. A number of the preoperative observations on blood sugar and metabolism were repeated, and the results are described later. Although the patient showed evidence of a slight diabetic tendency as indicated by a sugar tolerance test, he tolerated a full diet with a normal fasting blood sugar and without glycosuria. He was discharged on February 22, 1935, in good condition except for a small sinus at the upper part of the wound which still drained thin fluid resembling pancreatic juice. His weight was $81.8 \mathrm{kgm}$., a loss of $14.9 \mathrm{kgm}$. compared with that on admission.

Examination on May 20, 1935, five months after operation, showed that the patient was well, and was without recurrence of the preoperative symptoms. The sinus had closed shortly after discharge. The fasting blood sugar was $111 \mathrm{mgm}$. per cent. A 24-hour specimen of urine contained no sugar. The weight was $80.8 \mathrm{kgm}$.

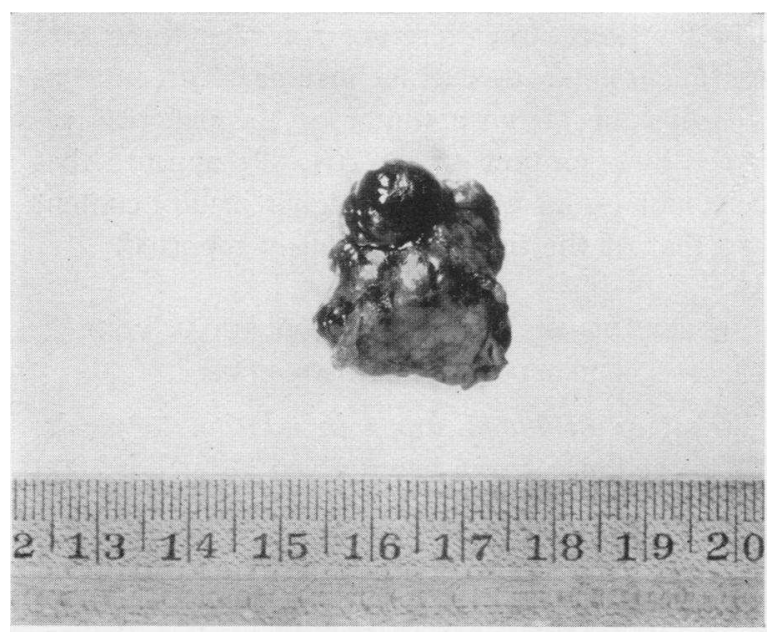

Fig. 1. Gross Appearance of the Tumor Removed FROM THE PANCREAS.

STUDIES OF THE TUMOR

Anatomical observations. The tumor as shown in Figure 1 appeared nodular, dark red in color, and firm in consistency, measuring 2.5 $\times 2.0 \times 1.5 \mathrm{~cm}$. in diameter. It weighed 4.41 grams. The anterior surface was covered by a thin fibrous capsule, while its posterior surface, i.e., that portion of the tumor in contact with the gland, was studded with small areas of pancreatic tissue. The cut surface was grayish, cellular in appearance and showed many congested blood vessels. Microscopically the tumor consisted of a diffuse solid growth of cells which were uniform in size, well differentiated and morphologically identical with those of Langerhans' islands (Figure 2). In some areas the cells were arranged in cords or trabeculae much like the structure of normal islands. Mitotic figures were not seen. The anterior surface was entirely encapsulated, but the posterior surface was cut across irregularly, and in certain areas, immediately beneath the capsule groups of pancreatic acini were present.

Biologic assay for insulin. The method of extraction used was that of Best, Jephcott and Scott (2). A portion of the tumor weighing 1.92 grams was extracted, and the volume of extract made up to $20 \mathrm{cc}$. The assay was done on two rabbits of comparable weight which had been deprived of food for 24 hours prior to injection. As seen from Table I, the extent and duration of hypo-

TABLE I

Results of assay of extract of the tumor for insulin on rabbits

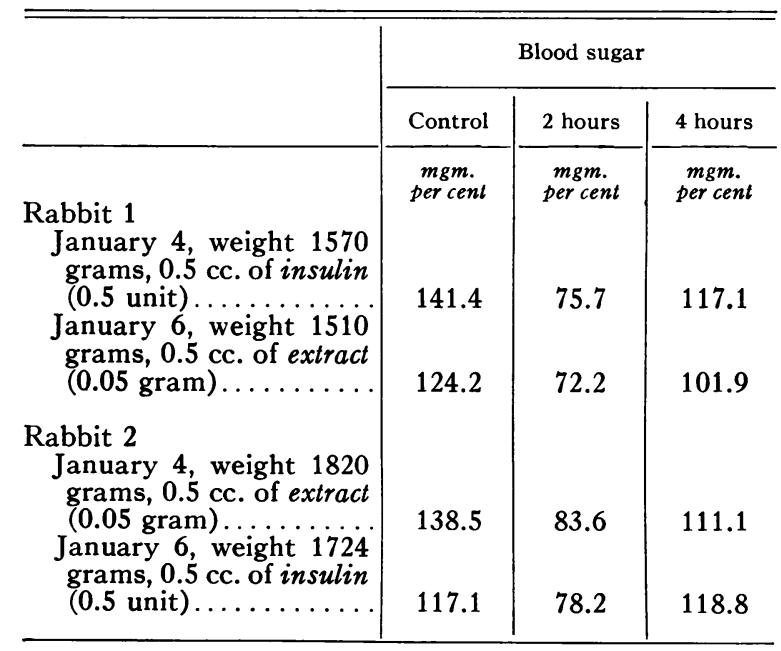

glycemia in both rabbits after the injection of tumor extract happened to approximate those after 0.5 unit of insulin. Therefore the tumor tissue was considered to contain approximately 10 units of insulin per gram. According to Best, Jephcott and Scott, beef pancreas yields on the 


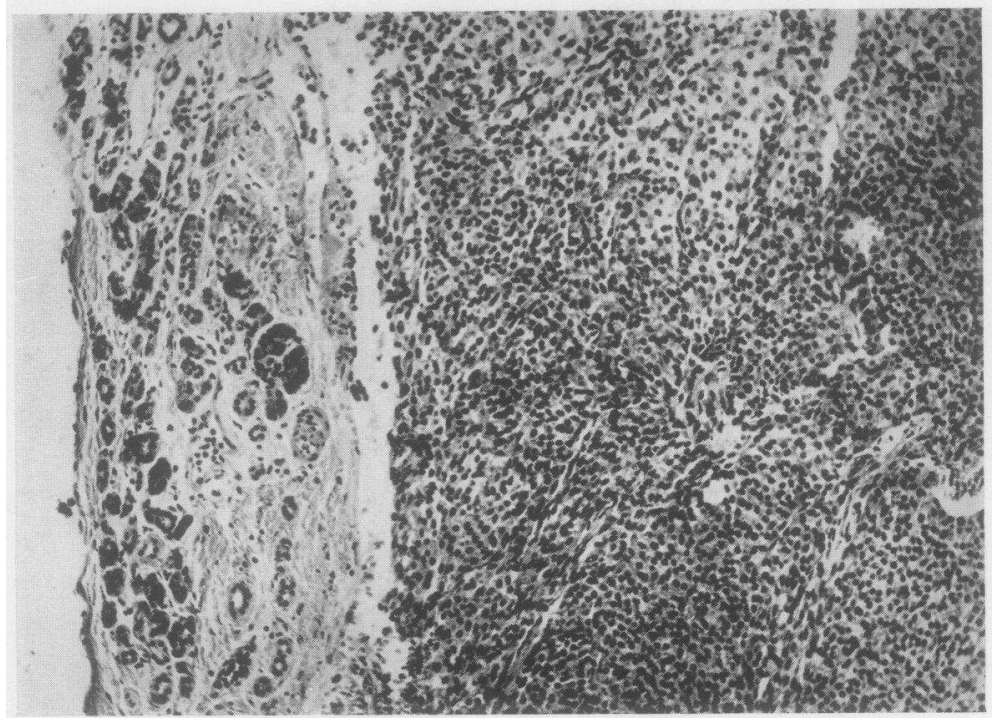

Fig. $2 A$. Photomicrograph of a Section near the Periphery of the Tumor Showing Acinar Tissue in the Capsule (left) and Tumor Tissue with Trabecula Formation (Right).

Magnification 111 times.

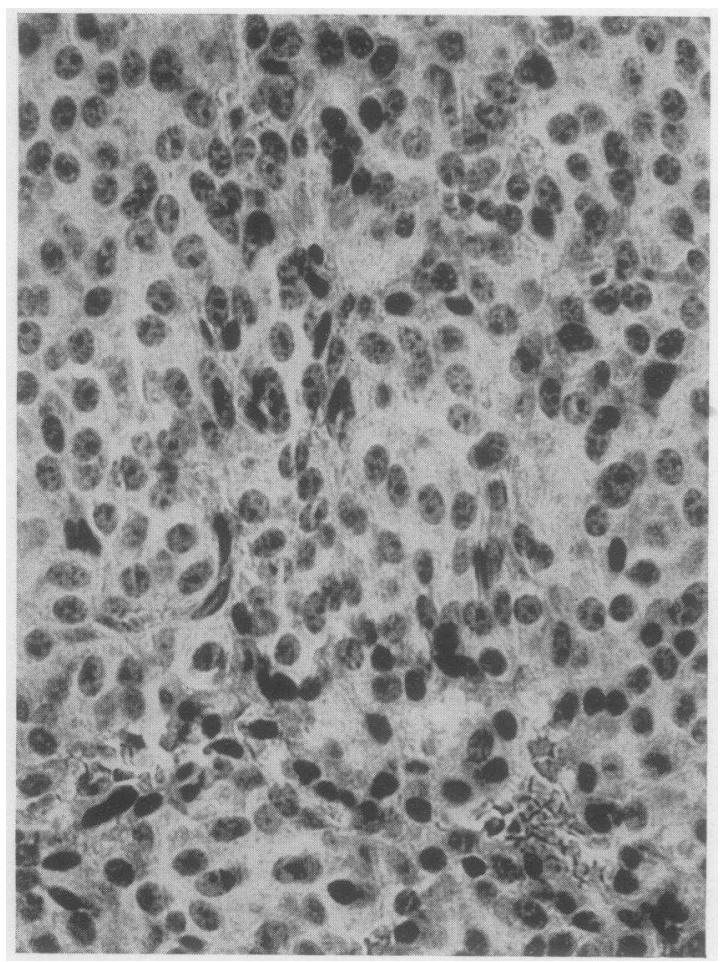

Fig. 2 B. Photomicrograph of a Section Showing Cytology of the Tumor in Greater Detail.

Magnification 445 times. average 3,000 units of insulin per $\mathrm{kgm}$. or 3 units per gram as determined by their method. The high insulin content of the tumor justifies the diagnosis of hyperinsulinism in this patient.

In the literature, there are recorded three successful attempts to extract insulin or an insulinlike substance from a tumor of the pancreas removed at operation $(5,8,26)$. It appears that the tumor in our case had a higher insulin content than that of the tumors previously reported.

\section{OBSERVATIONS ON THE BLOOD SUGAR AND RESPIRATORY METABOLISM}

Behavior of blood sugar in relation to meals. While the patient was being given a diet of 3,000 calories with 473 grams of carbohydrate distributed evenly among five meals, the capillary blood sugar was determined hourly throughout 24 hours by the Folin-Wu method ( 7 ) adapted to $0.1 \mathrm{cc}$. samples. The results are plotted in Figure 3, from which one notes that the blood sugar rose to a maximum within 1 to 3 hours after each meal. The maxima, which varied from 65 to 115 mgm. per cent, were below normal after meals, although the values were low to start with. The more significant abnormality lies in the fail- 
ure of the blood sugar to maintain a normal level during the postabsorptive period. Within 4 to 5 hours after each meal when absorption could

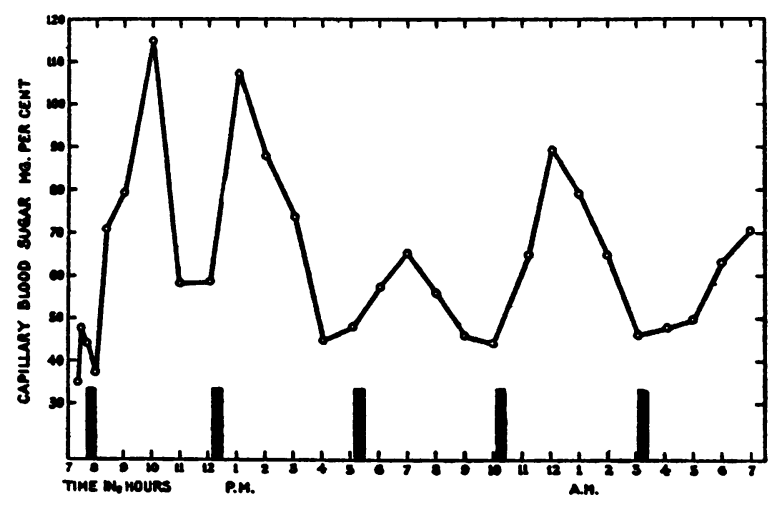

Fig. 3. Hourly Blood Sugar throughout 24 Hours in Relation to Meals Which are Indicated by Vertical. Bars.

hardly be complete it promptly fell to 44 to 58 mgm. per cent. If, therefore, meals had been delayed, it is reasonable to suppose that the level would have continued to fall until symptoms occurred. Therefore, the condition can be characterized as one of pronounced postabsorptive hypoglycemia in which frequent feedings were necessary to prevent the development of symptoms.

Correlation between the level of blood sugar and the clinical picture. On one morning with breakfast omitted, the patient was observed carefully, and the capillary blood sugar, blood pressure and pulse rate were determined at approximately 10-minute intervals. As seen from Figure 4, the observations were commenced at 8:00 a.m. when the patient was quiet and mentally clear with the blood sugar fluctuating at 45 to $50 \mathrm{mgm}$. per cent. He remained in this condition for about 25 to 30 minutes, after which without appreciable change in the level of the blood sugar. he became slightly drowsy, but easily arousable. The drowsiness gradually deepened so that in another 30 minutes when awakened he again fell asleep and began snoring at once. The blood sugar level remained practically unchanged. The period of profound drowsiness lasted 25 minutes before it passed into a stage of excitement. Then the patient became restless, opened his eyes in a staring manner and yawned repeatedly. The fists were clenched tightly, and the legs were moved about purposelessly. At times, fine twitchings of the muscles of the hands and face were noticed. The patient still seemed to recognize loud calls or commands, but was unable to answer or act upon them. The blood sugar level tended to fall somewhat, slightly below $45 \mathrm{mgm}$. per cent. This period lasted 10 minutes before active generalized clonic convul-

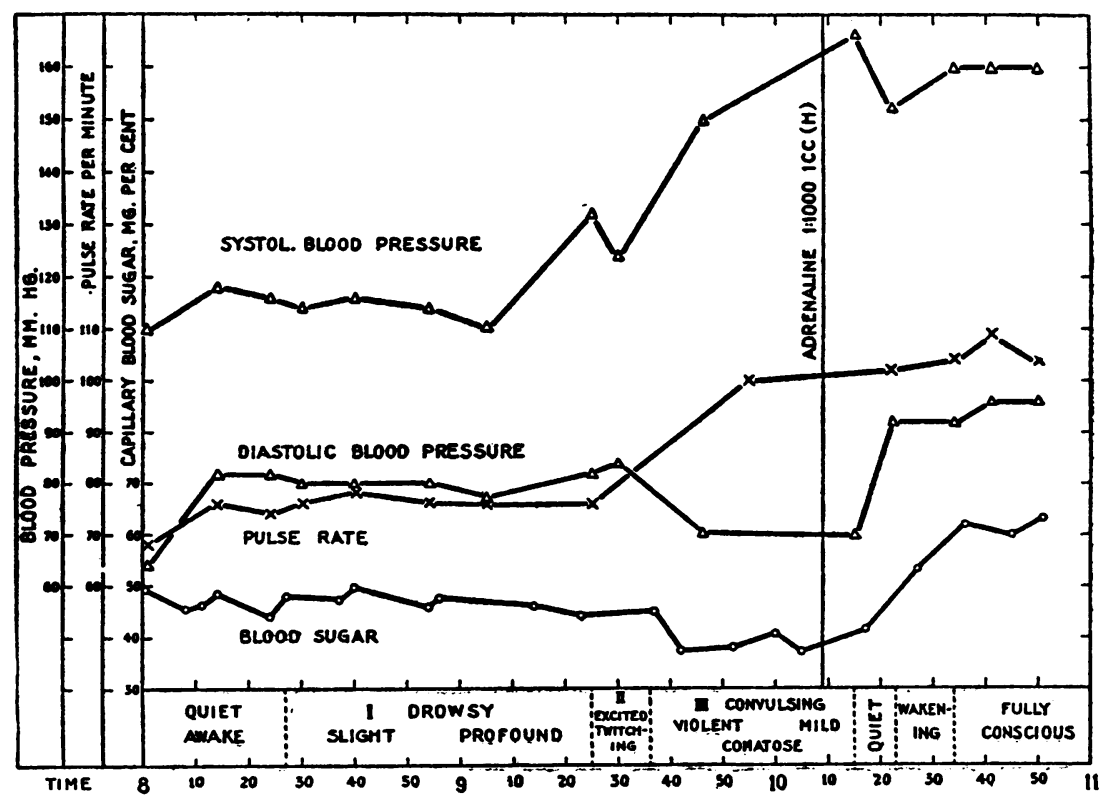

Fig. 4. Correlation between Level of Blood Sugar and Mental State. Blood Pressure and Pulse Rate also Indicated. 
sions began. The convulsions increased gradually in violence, the patient's whole body being thrown about the bed with such force that several men were required to hold him down. Breathing was stertorous, with frothing at the mouth. Violent seizures continued for 15 minutes before they gave place to milder convulsive movements of the limbs. With the onset of convulsions the blood sugar dropped to about 37 to $40 \mathrm{mgm}$. per cent. The blood pressure began to rise during the excitement and reached 150/70 during the convulsions. The pulse rate also was increased. One cubic centimeter of $1: 1,000$ solution of adrenalin given subcutaneously was followed in 5 minutes by a subsidence of the convulsions and in 15 minutes, by consciousness.

It seems that the hypoglycemic syndrome in this patient can be divided conveniently into three stages. The first stage was characterized by drowsiness and a gradually deepening depression. The second stage was ushered in by excitement which progressed into the convulsive seizures of the third stage. During the first stage which lasted for an hour there was no significant decrease of blood sugar compared with that of the period of relative well-being. Even when the second stage was reached, the lowering of blood sugar was slight, if any. It was not until after the convulsions had started that definite further lowering of the blood sugar occurred. From these observations it may be inferred that hypoglycemia has to be maintained for a certain length of time, which in this patient amounted to over two hours, before the central nervous system suffers sufficiently to manifest itself by convulsions. lt seems that besides the level of the hypoglycemia, the duration is an important determining factor in the symptomatic manifestations. Unfortunately, our observations did not extend over a sufficiently long period prior to the symptoms to enable us to estimate accurately the duration of the critical level of blood sugar necessary to initiate an attack.

The effect of adrenalin. A detailed study of the blood sugar level and its relation to symptomatic manifestations following the administration of adrenalin is given in Figure 5. The efficacy of adrenalin in relieving the hypoglycemic syndrome, a well known phenomenon, was demonstrated clearly in this case. With the patient

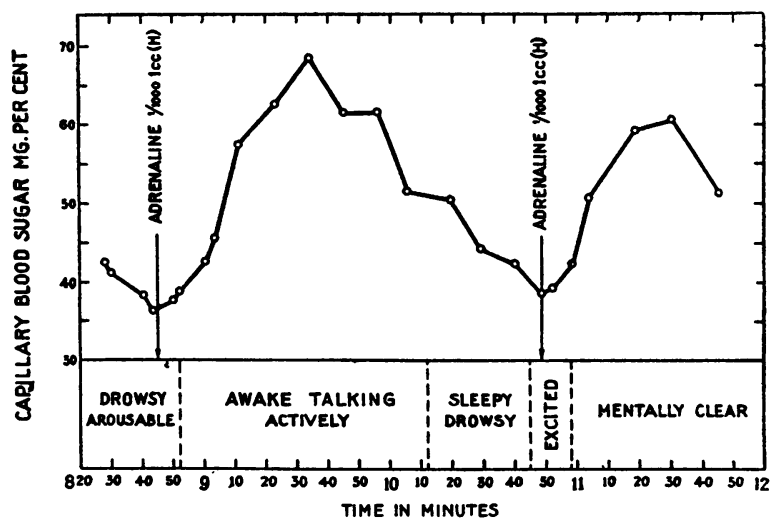

Fig. 5. Efficacy of Adrenalin in Raising Blood Sugar and Relieving Symptoms.

mentally drowsy and the blood sugar at the low level of $36 \mathrm{mgm}$. per cent, $1 \mathrm{cc}$. of adrenalin injected hypodermically was followed within 10 minutes by a return of consciousness associated with a rise of the blood sugar to $42 \mathrm{mgm}$. per cent. A maximum level of $68.6 \mathrm{mgm}$. per cent was reached about 45 minutes after the injection. From then on it commenced to fall, and $85 \mathrm{~min}$ utes after the injection it reached a level of approximately $50 \mathrm{mgm}$. per cent at which time the patient again began to feel drowsy. Two hours after the injection the blood sugar was back to the original low level, and the patient once more was in a semicomatose condition. A second injection of adrenalin at this point brought about a similar reaction, although the maximum level of blood sugar attained was somewhat lower.

It may be noted here that there apparently was a difference in the blood sugar level referable to a given mental state depending on whether the blood sugar was increasing or decreasing. During the ascent of the curve following the injection of adrenalin, consciousness was almost regained at $42 \mathrm{mgm}$. per cent, while during its descent drowsiness supervened at $50 \mathrm{mgm}$. per cent. The difference was probably significant, although no attempt was made to determine the true glucose content of blood which might not have shown such discrepancies.

The action of adrenalin was studied further by the simultaneous determination of the venous blood sugar and serum inorganic phosphorus (6) following the administration of this drug both preoperatively and after convalescence from the operation. As shown in Figure 6, the adrenalin 
hyperglycemia before operation, as in previous observations, reached its peak 40 minutes after injection, and the blood sugar returned to the in-

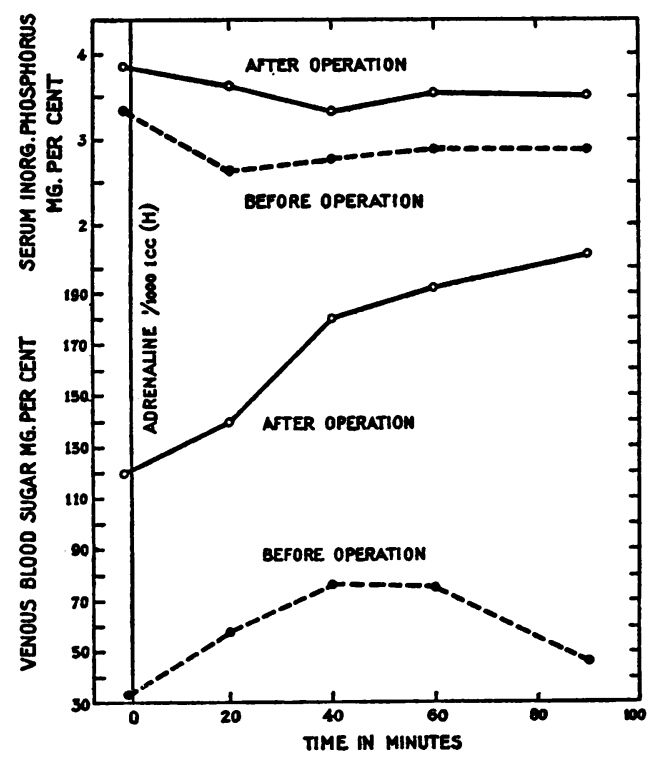

Fig. 6. Comparison of the Effect of Adrenalin on Blood Sugar and Serum Inorganic Phosphorus Before aNd after Operative Removal OF the TUmor OF ISLANDS OF LANGERHANS.

itial level in 90 minutes. However, after operation, at which the source of excess insulin was removed, adrenalin caused a much more extensive and prolonged rise in the blood sugar; at $90 \mathrm{~min}$ utes after injection when the study was terminated, a maximum value of $198 \mathrm{mgm}$. per cent was obtained. The serum inorganic phosphorus curve before operation was on a lower level and showed a more definite decline following the administration of adrenalin than that obtained by the same procedure after excision of the tumor.

These observations may be summarized by saying that although adrenalin was very promptly effective in combating the hypoglycemic syndrome, thus acting as a true antagonist to insulin, its action was considerably curtailed and shortened in the presence of excess insulin. The fact that adrenalin was repeatedly effective indicated that a considerable store of glycogen in the liver or other tissues was available for conversion into glucose.

Effect of pituitrin, pitressin, and ephedrine. One cubic centimeter of pituitrin (Parke, Davis and Co.) was given hypodermically on one occasion when the blood sugar was only $38 \mathrm{mgm}$. per cent and the patient was emerging from drowsiness into excitement; 15 minutes later the blood sugar rose to $42 \mathrm{mgm}$. per cent, and the patient was somewhat clearer for a short while (10 minutes) before returning to the pre-injection state. One and a half cubic centimeters of pitressin (Parke, Davis and Co.) was then given subcutaneously, and its action was observed to be similarly slight and doubtful. On another occasion ephedrine was used (100 mgm. hypodermically) without the slightest effect on the course of the patient's symptoms or the level of the blood sugar.

Effect of levulose. One morning when the patient was slightly drowsy and the blood sugar was $48 \mathrm{mgm}$. per cent, he was given, instead of his usual breakfast, 50 grams of levulose dissolved in $250 \mathrm{cc}$. of water. The drowsiness persisted and gradually deepened and 70 minutes after the ingestion of levulose restlessness set in and progressed to mild convulsive attacks. The blood sugar, however, rose to $55 \mathrm{mgm}$. per cent in 30 minutes and fell to $44 \mathrm{mgm}$. per. cent in $70 \mathrm{~min}$ utes at which time mild convulsions supervened. This ineffectiveness of levulose in combating the hypoglycemic syndrome is in conformity with the results of Cori (3) who showed that levulose cannot be utilized by the tissues until it first has been converted into glycogen by the liver. The slight rise of blood sugar probably represented levulose which was ineffective in counteracting the symptoms.

Comparison of the effect of glucose per rectum and by mouth. Although glucose often has been administered per rectum, doubt still exists as to whether it is absorbed through this route. Our patient afforded an excellent indicator with which to test the efficacy of the absorption of glucose by rectum inasmuch as very slight changes in the level of the blood sugar were manifested by marked changes in his mental state. As indicated in Figure 7, $600 \mathrm{cc}$. of 10 per cent solution of glucose given per rectum in three installments within a period of one hour did not prevent the gradual lowering of the blood sugar or the progression of drowsiness to the subsequent state of excitement and convulsions. This is a sharp contrast to the efficacy of glucose administered by mouth, by which route even much smaller amounts 


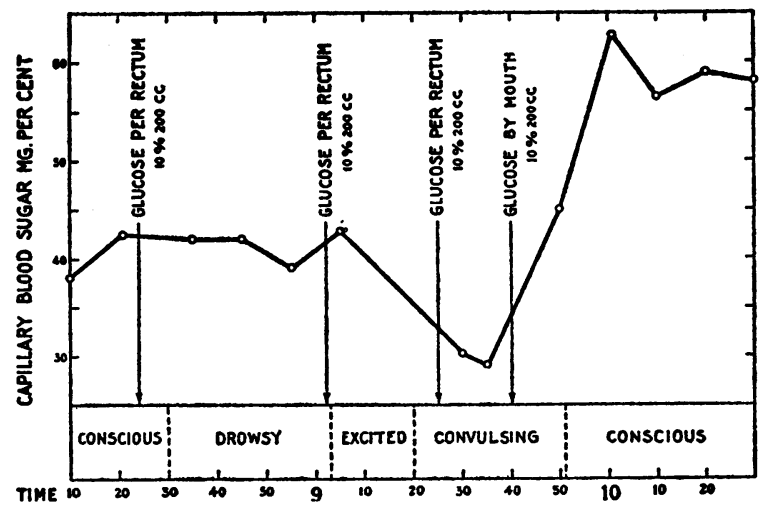

Fig. 7. InefFectiveness of GLUCOSE PER Rectum in Combating the Hypoglycemic Syndrome in Contrast to the Efficacy of Glucose by Mouth.

of glucose brought about immediate amelioration of symptoms and a rise of the blood sugar. This observation indicates that glucose in this concentration per rectum is not absorbed or is absorbed so slowly that physiologic effects are not demonstrable. This conclusion is in agreement with that of Scott and Zweighaft (21).

Effect of glucose on blood sugar, metabolic rate and respiratory quotient before and after operation. The study consisted of half-hourly analyses of the capillary blood sugar, hourly determinations of the metabolic rate and estimations of urinary nitrogen, both before and for 4 hours after the ingestion of 170 grams of glucose. The expiratory gas was collected in a Tissot gasometer for a period of 10 to 15 minutes each time and analyzed for $\mathrm{O}_{2}$ and $\mathrm{CO}_{2}$ in a Haldane apparatus. Urinary nitrogen was determined by the Kjeldahl method. The data on blood sugar, respiratory quotient, caloric output, and calculated composition of metabolic mixture during the experimental periods are presented in Figure 8 and Tables II and III.

In Figure 8, the blood sugar curve before operation is seen to deviate from normal in two respects. First, the peak (156 mgm. per cent) was not reached until two hours after the ingestion of glucose. Second, after a normal level had been reached at the end of three hours the curve continued to fall to the level of $51 \mathrm{mgm}$. per cent at the end of the fourth hour, a low level comparable to that which existed before glucose was administered. It seems that the excess insulin present in the blood stream prevented a more prompt attainment of the maximal level. As soon as this was reached, more insulin was called forth. The excess insulin together with the diminishing amount of glucose entering the blood stream from

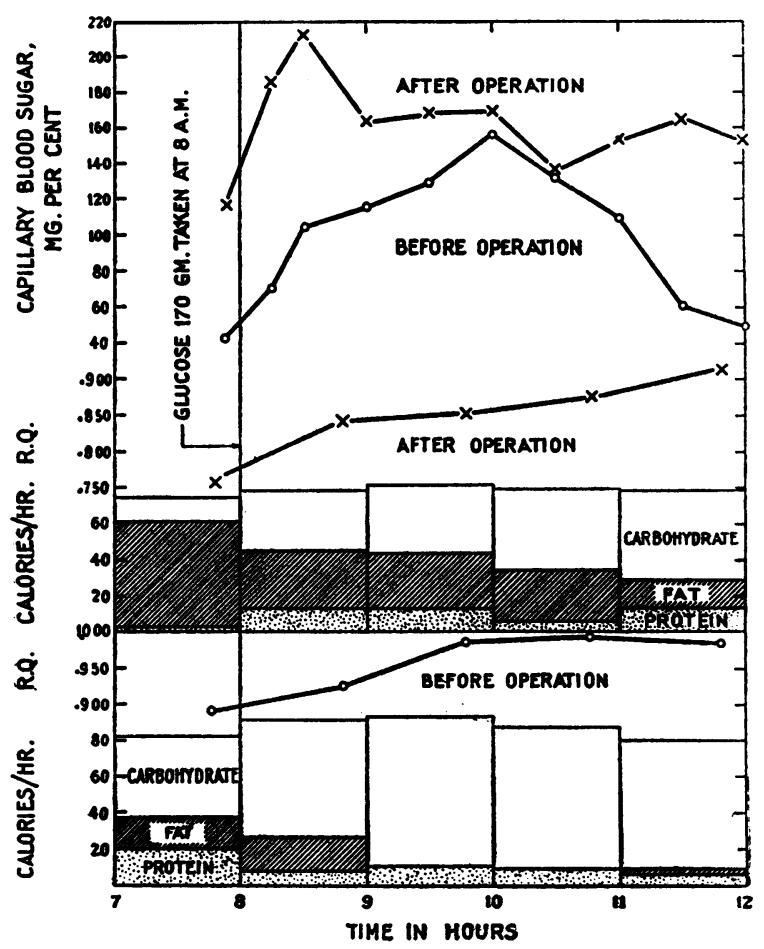

Fig. 8. The Effect of Glucose Ingestion on Blood Sugar, Respiratory Quotient, Metabolic Rate, and Composition of the Metabolic Mixture before and AFTER OpERATION.

TABLE II

Effect on respiratory quotient and metabolic rate of 170 grams glucose ingested at 8:00 a.m.

\begin{tabular}{|c|c|c|c|c|c|c|c|c|c|c|c|c|}
\hline \multirow[t]{2}{*}{ Time } & \multicolumn{2}{|c|}{$\begin{array}{l}\text { Total } \\
\text { respiratory } \\
\text { quotient }\end{array}$} & \multicolumn{2}{|c|}{$\begin{array}{l}\text { Nonprotein } \\
\text { respiratory } \\
\text { quotient }\end{array}$} & \multicolumn{2}{|c|}{$\begin{array}{c}\text { Calories } \\
\text { per } \\
\text { bour }\end{array}$} & \multicolumn{2}{|c|}{$\begin{array}{l}\text { Calories } \\
\text { per } \\
24 \text { hours }\end{array}$} & \multicolumn{2}{|c|}{$\begin{array}{l}\text { Metar } \\
\text { bolic } \\
\text { rate }\end{array}$} & \multicolumn{2}{|c|}{$\begin{array}{l}\text { Increase } \\
\text { over basal } \\
\text { rate }\end{array}$} \\
\hline & $A^{*}$ & Pt & $\mathbf{A}^{*}$ & $\mathrm{Pt}$ & $\mathbf{A}^{*}$ & $\mathrm{Pt}$ & $\mathbf{A}^{*}$ & Pt & $\mathrm{A}^{*}$ & $\mathbf{P t}$ & $\mathbf{A}^{*}$ & $\mathrm{Pt}$ \\
\hline $\begin{array}{l}\text { a.m. } \\
7-8\end{array}$ & 0.883 & 0.765 & 0.910 & 0,763 & 82.4 & 74.7 & 1977 & 1793 & $\begin{array}{c}\text { per } \\
\text { cent } \\
3.0\end{array}$ & $\begin{array}{l}\text { per } \\
\text { cent } \\
0.0\end{array}$ & $\begin{array}{c}\text { per } \\
\text { cent } \\
0\end{array}$ & \\
\hline $\begin{array}{c}8-9 \\
9-11 \\
10-11 \\
11-12\end{array}$ & $\begin{array}{l}0.925 \\
0.987 \\
0.992 \\
0.972\end{array}$ & $\begin{array}{l}0.848 \\
0.856 \\
0.878 \\
0.914\end{array}$ & $\begin{array}{l}0.937 \\
1.010 \\
1.014 \\
0.987\end{array}$ & $\begin{array}{l}0.855 \\
0.866 \\
0.884 \\
0.931\end{array}$ & $\begin{array}{l}91.5 \\
92.1 \\
86.6 \\
80.1\end{array}$ & \begin{tabular}{|l|}
77.7 \\
80.8 \\
78.6 \\
78.8
\end{tabular} & \begin{tabular}{|l|}
2079 \\
1924
\end{tabular} \mid & $\left|\begin{array}{l}1866 \\
1941 \\
1885 \\
1892\end{array}\right|$ & $\begin{array}{r}14.4 \\
15.1 \\
8.2 \\
0.1\end{array}$ & $\begin{array}{l}4.0 \\
8.2 \\
5.2 \\
5.5\end{array}$ & $\begin{array}{r}11.0 \\
11.8 \\
5.1 \\
-2.8\end{array}$ & $\begin{array}{l}4.0 \\
8.2 \\
5.2 \\
5.5\end{array}$ \\
\hline
\end{tabular}

* A, before operation, height $172 \mathrm{~cm}$., weight $95.0 \mathrm{kgm}$., surface area 2.08 square meters, Aub-DuBois standard 80.0 calories per hour.

$\dagger P$, after operation, height $172 \mathrm{~cm}$., weight $82 \mathrm{kgm}$., surface area 1.94 square meters, Aub-DuBois standard 74.7 calories per hour. 
TABLE III

Combustion of protein (from urinary nitrogen), carbohydrate and fat (from nonprotein respiratory quotient) before and after ingestion of 170 grams glucose at 8 a.m.*

\begin{tabular}{|c|c|c|c|c|c|c|c|c|c|c|c|c|}
\hline \multirow{2}{*}{ Time } & \multicolumn{4}{|c|}{ Protein } & \multicolumn{4}{|c|}{ Carbohydrate } & \multicolumn{4}{|c|}{ Fat } \\
\hline & \multicolumn{2}{|c|}{ A } & \multicolumn{2}{|c|}{$\mathrm{P} \ddagger$} & \multicolumn{2}{|c|}{ Af } & \multicolumn{2}{|c|}{$\mathbf{P} \ddagger$} & \multicolumn{2}{|c|}{ At } & \multicolumn{2}{|c|}{ P } \\
\hline $\begin{array}{l}\text { a.m. } \\
7-8\end{array}$ & $\begin{array}{c}\text { grams } \\
4.48\end{array}$ & \begin{tabular}{|c} 
calories \\
19.0
\end{tabular} & $\begin{array}{r}\text { grams } \\
0.46\end{array}$ & $\begin{array}{c}\text { calories } \\
2.0\end{array}$ & $\begin{array}{c}\text { grams } \\
11.0\end{array}$ & $\begin{array}{c}\text { calories } \\
46.0\end{array}$ & $\begin{array}{c}\text { grams } \\
3.4\end{array}$ & $\begin{array}{c}\text { calories } \\
14.1\end{array}$ & $\begin{array}{c}\text { grams } \\
1.84\end{array}$ & $\begin{array}{c}\text { calories } \\
17.4\end{array}$ & $\begin{array}{r}\text { grams } \\
6.19\end{array}$ & $\begin{array}{r}\text { calories } \\
58.6\end{array}$ \\
\hline $\begin{array}{c}8-9 \\
9-10 \\
10-11 \\
11-12 \\
\text { Total for last } 4 \text { hours }\end{array}$ & $\begin{array}{l}1.76 \\
2.30 \\
1.98 \\
1.37 \\
7.41\end{array}$ & $\begin{array}{r}7.4 \\
9.7 \\
8.4 \\
5.8 \\
31.3\end{array}$ & $\begin{array}{r}2.97 \\
2.79 \\
1.34 \\
3.12 \\
10.22\end{array}$ & $\begin{array}{r}12.6 \\
12.8 \\
5.3 \\
13.2 \\
43.9\end{array}$ & $\begin{array}{l}16.0 \\
19.7 \\
18.7 \\
17.0 \\
71.4\end{array}$ & $\begin{array}{r}65.9 \\
82.4 \\
78.2 \\
71.0 \\
297.5\end{array}$ & $\begin{array}{r}7.9 \\
8.8 \\
11.6 \\
12.0 \\
40.3\end{array}$ & $\begin{array}{r}33.0 \\
37.0 \\
44.4 \\
50.2 \\
164.6\end{array}$ & $\begin{array}{l}1.94 \\
0.0 \\
0.0 \\
0.35 \\
2.29\end{array}$ & $\begin{array}{r}18.2 \\
0.0 \\
0.0 \\
3.3 \\
21.5\end{array}$ & $\begin{array}{r}3.39 \\
3.27 \\
3.06 \\
1.63 \\
11.35\end{array}$ & $\begin{array}{r}32.1 \\
31.0 \\
28.9 \\
15.4 \\
107.4\end{array}$ \\
\hline
\end{tabular}

* Calculation according to Lusk (16); protein equivalent to 4.24 calories; carbohydrate 4.18 calories; and fat 9.46 calories per gram.

$\dagger \mathrm{A}$, before operation, 42.6 per cent of the glucose ingested was burned during 4 hours; protein contributed 8.9 per cent, carbohydrate 85.0 per cent, and fat 6.1 per cent of the total energy metabolism during 4 hours subsequent to glucose administration.

$\ddagger P$, after operation, 23.7 per cent of the glucose ingested was burned during 4 hours; protein contributed 13.8 per cent, carbohydrate 52.1 per cent, and fat 34.1 per cent of the total energy metabolism during 4 hours subsequent to glucose administration.

the gastro-intestinal tract drove the blood sugar down to the low level. The curve obtained after operation was markedly different in that the peak of $214 \mathrm{mgm}$. per cent was reached in half an hour and a level between 133 and 169 mgm. per cent was maintained during the subsequent 3 hours. The high maximum and sustained hyperglycemia indicate an impaired mechanism for the removal of glucose suggestive of the prediabetic state, although the fasting blood sugar was normal and urinary sugar was absent.

The metabolic rate increased after the administration of glucose, the extent of the increase (specific dynamic action) being greater before (12 per cent) than after operation ( 8 per cent). During the period of hyperinsulinism the respiratory quotient before glucose $(0.883)$ was higher than normal and went up nearly to unity after glucose administration, while after operation the quotient before glucose $(0.765)$ was lower than normal and rose only to 0.914 during the fourth hour after the ingestion of this substance. The marked lowering of the respiratory quotient after operation indicates the profound changes in the composition of the metabolic mixture brought about by the removal of the pancreatic adenoma.

Prior to operation and during the 4 hours following the ingestion of 170 grams of glucose, 71.4 grams carbohydrate, 7.4 grams protein and 2.3 grams fat were burned; while after operation,
40.3 grams carbohydrate, 10.2 grams protein and 11.4 grams fat were metabolized under comparable conditions (Table III, Figure 8). In other words, prior to operation, when there was an excess of insulin the metabolism of carbohydrates played a more dominating rôle and proceeded at a faster rate in contrast to the situation after operation in which carbohydrate was used more slowly and protein and fat were drawn upon to a greater extent.

Linder, Hiller and Van Slyke (15) fed 90 to 100 grams of glucose to normal fasting men, and determined their respiratory quotients and total metabolism. In four hours only 20 to 30 per cent of the glucose had been burned, although apparently all had been absorbed. In our patient glucose combustion prior to operation was 42.6 per cent, exceeding normal limits; while after operation it amounted to 23.7 per cent, which was fairly normal.

The sparing of fat and protein as a result of the predominant utilization of carbohydrate by virtue of the excess insulin, together with overeating, probably accounts for the marked obesity this patient exhibited prior to surgical treatment.

\section{COMMENT}

The hypoglycemic syndrome is a symptom complex associated with abnormally low blood sugar. The level of blood sugar at which symptoms oc- 
cur varies from case to case. Of the large series of cases of hyperinsulinism compiled by Whipple and Frantz (25), the minimal blood sugar ranged from 4 to 58 , with the majority falling between 30 and $45 \mathrm{mgm}$. per cent. The wide range is accounted for partly by the different methods used in the determinations and partly by individual susceptibility to the effects of hypoglycemia. This susceptibility apparently varies not only with age but with other factors as well, so that different responses may be obtained from the same individual on different occasions. Moreover, the ascending threshold for clear consciousness is lower than the descending threshold. There was a difference of over $15 \mathrm{mgm}$. per cent in our patient.

The symptoms associated with hypoglycemia are protean. If a careful history is taken, the attacks are found almost always to be associated with omission or delay of meals. Overpowering hunger and weakness frequently initiate the trouble, and the patients or their relatives discover sooner or later that food aborts or relieves attacks. Often larger and more frequent meals are taken to prevent symptoms. Overeating together with the protein- and fat-sparing action of insulin results in obesity.

The symptoms of hypoglycemia, though variable, are chiefly vasomotor, such as sweating, flushes, and an increase in the pulse rate and blood pressure; and psychic disturbances, such as drowsiness, excitement, delirium, maniacal seizures, convulsions and coma. Weakness and fatigue are prominent. Rynearson and Moersch (20) tabulated the symptoms. The picture during an attack may vary in individual cases.

From the extensive literature on carbohydrate metabolism reviewed by Cori (4) and Shaffer and Ronzoni (22), it has become generally accepted that the blood sugar is maintained normally at a concentration of approximately $100 \mathrm{mgm}$. per cent mainly through the interplay between insulin and epinephrine. A rise in blood sugar elicits a secretion of insulin which accelerates conversion of glucose into glycogen and carbohydrate oxidation in the liver, muscles and presumably all tissues, while a fall in blood sugar is followed by a discharge of epinephrine which increases the rate of hydrolysis of liver glycogen to glucose and conversion of muscle glycogen lactate. The latter is reconverted into glycogen by the liver thereby contributing indirectly to the sugar of the blood. Macleod (18) postulates a sugar regulating center in the pons. Its stimulation by hyperglycemia causes the secretion of insulin by way of the vagus; while hypoglycemia results in sympathetic stimulation and the outpouring of epinephrine.

Wauchope (24) has summarized the causes of hypoglycemia under four main headings: First, hyperinsulinism which may be functional, or on the basis of adenoma, carcinoma or hyperplasia of pancreatic islets; or therapeutic, as a result of an overdosage of insulin. Second, lack of opposing hormones, as in Addison's disease, myxedema, and pituitary cachexia. Third, deficient glycogen store due to liver disease $(13,14)$, severe exercise, excessive drain (renal diabetes or lactation), or starvation. Fourth, disturbances of the regulating center in the pons (vagotonia).

Before a diagnosis of hyperinsulinism is made, all the other conditions enumerated above should be considered and excluded. This was done in our case without much difficulty. The finding of an adenoma of the pancreas composed of cells of the islands of Langerhans, the abatement of symptoms after excision of the tumor and finally the presence of large amounts of insulin in the biological assay of the tumor tissue established beyond doubt that the anatomical basis of the hypoglycemia in our patient was an islet cell adenoma.

As regards treatment, frequent meals rich in carbohydrate usually suffice to avert the symptoms when these are slight and infrequent. Harris (11), however, considers that a diet relatively poor in carbohydrate and rich in fat, with moderate protein, is more effective in reducing the production of insulin by the pancreas. Suprarenal extract by mouth was given in three cases as an adjuvant (19), but it did not appear to offer much advantage over diet alone. Thyroid has been tried without benefit (23).

For emergency treatment during an attack, epinephrine administered hypodermically and glucose by mouth constitute two potent therapeutic measures. Both act promptly. While glucose has a more lasting effect, epinephrine possesses 
the advantage of being administered easily during coma or convulsions which may render the ingestion of glucose impossible. It is important to remember that glucose per rectum is ineffective. The effect of levulose is doubtful, and presumably that of galactose as well. Pituitrin, pitressin and ephedrine are unreliable.

When the symptoms persist and increase, surgical attack on the pancreas becomes the treatment of choice. In all cases in which an adenoma has been found at operation and removed, relief from symptoms has been complete. Of the 15 cases without demonstrable tumor (25) in which a partial resection of the pancreas was carried out, improvement was noticed in 5. These were instances in which a large portion of the gland was removed. Graham and Hartmann (9) and more recently McCaughan (17) have advocated subtotal pancreatectomy for cases of hyperinsulinism in which a tumor is not demonstrable. It seems reasonable to believe that, as in the case of the thyroid, satisfactory results may not be obtained unless a subtotal excision of the gland is carried out.

It does not seem necessary to go into the details of surgical technic, as these are available elsewhere $(8,17,25)$. It should, however, be emphasized that exposure must be adequate and exploration of the pancreas thorough, as multiple adenomata were found in four of the seventeen cases reported previously $(8,25)$. In our case a long left rectus incision and division of the gastrocolic omentum allowed satisfactory access to the gland. Others have preferred to use a transverse incision (25) or to approach the pancreas by the supragastric route (9). In instances in which mobilization or partial resection of the pancreas is attempted and serious difficulty is encountered due to hemorrhage from branches of the splenic vessels, we would like to suggest simple ligation of the splenic artery near its point of origin as a satisfactory means of controlling the flow of blood. Experience with this procedure as a substitute for splenectomy in certain instances has convinced us that ligation of this vessel is by no means an indication for subsequent removal of the spleen.

\section{SUMMARY}

A case of chronic postabsorptive hypoglycemia associated with coma and convulsive seizures is reported. On surgical exploration a small tumor of the pancreas was found, the excision of which led to complete relief of the symptoms. The tumor was composed of cells of the islands of Langerhans, and yielded considerably more insulin than normal pancreatic tissue. Detailed studies of the blood sugar and metabolism before and after operation are presented. Evidence is adduced showing that the hypoglycemia was, in a large measure, related to the fact that the combustion of carbohydrate proceeded at a faster rate and played a more dominating rôle in energy metabolism than is normal, thus sparing fat and protein. This action, combined with overeating, produced obesity. Glucose by mouth and adrenalin hypodermically were promptly efficacious in combating the hypoglycemia. Pituitrin, pitressin, ephedrine, levulose by mouth and glucose per rectum were ineffective.

\section{BIBLIOGRAPHY}

1. Banting, F. G., and Best, C. H., The internal secretion of the pancreas. J. Lab. and Clin. Med., 1922, 7, 251.

2. Best, C. H., Jephcott, C. M., and Scott, D. A., Insulin in tissues other than the pancreas. Am. J. Physiol., 1932, 100, 285.

3. Cori, C. F., The fate of sugar in the animal body. III. The rate of glycogen formation in the liver of normal and insulinized rats during the absorption of glucose, fructose and galactose. J. Biol. Chem., 1926, 70, 577.

4. Cori, C. F., Mammalian carbohydrate metabolism. Physiol. Rev., 1931, 11, 143.

5. Derick, C. L., Newton, F. C., Schulz, R. Z., Bowie, M. A., and Pokorny, N. A., Spontaneous hyperinsulinism. Report of a case of hyperinsulinism cured by surgical intervention. New England J. Med., 1933, 208, 293.

6. Fiske, C. H., and Subbarow, Y., The colorimetric determination of phosphorus. J. Biol. Chem., 1925, 66, 375.

7. Folin, O., and Wu, H., A system of blood analysis, Supplement 1. A simplified and improved method for determination of sugar. J. Biol. Chem., 1920, 41, 367.

8. Graham, E. A., and Womack, N. A., The application of surgery to the hypoglycemic state due to islet tumors of pancreas and to other conditions. Surg., Gynec. and Obst., 1933, 56, 728. 
9. Graham, E. A., and Hartmann, A. F., Subtotal resection of the pancreas for hypoglycemia. Surg. Gynec. and Obst., 1934, 59, 474.

10. Harris, S., Hyperinsulinism and dysinsulinism. J. A. M. A., 1924, 83, 729.

11. Harris, S., Hyperinsulinism, a definite disease entity. J. A. M. A., 1933, 101, 1958.

12. Howland, G., Campbell, W. R., Maltby, E. J., and Robinson, W. L., Dysinsulinism: convulsions and coma due to islet cell tumor of pancreas with operation and cure. J. A. M. A., 1929, 93, 674.

13. Judd, E. S., Kepler, E. J., and Rynearson, E. H., Spontaneous hypoglycemia: Report of two cases associated with fatty metamorphosis of the liver. Am. J. Surg., 1934, 24, 345.

14. Kramer, B., Grayzel, H. G., and Solomon, C. J., Chronic hypoglycemia in childhood. J. Pediat., 1934, 5, 299.

15. Linder, G. C., Hiller, A., and Van Slyke, D. D., Carbohydrate metabolism in nephritis. J. Clin. Invest., 1925, 1, 247.

16. Lusk, G., The Science of Nutrition. Saunders, Philadelphia, 1923, 3d ed., p. 60.

17. McCaughan, J. M., Subtotal pancreatectomy for hyperinsulinism. Operative technic. Ann. Surg., 1935, 101, 1336.
18. Macleod, J. J. R., The control of carbohydrate metabolism. Bull. Johns Hopkins Hosp., 1934, 54, 79.

19. Nielsen, J., and Eggleston, E. L., Functional dysinsulinism with epileptiform seizures. J. A. M. A., 1930, 94, 860.

20. Rynearson, E. H., and Moersch, F. P., Neurologic manifestations of hyperinsulinism and other hypoglycemic states. J. A. M. A., 1934, 103, 1196.

21. Scott, E. L., and Zweighaft, J. F. B., Blood sugar in man following the rectal administration of dextrose. Arch. Int. Med., 1932, 49, 221.

22. Shaffer, P. A., and Ronzoni, E., Carbohydrate metabolism. Annual Rev. Biochem., 1932, 1, 247.

23. Tedstrom, M. K., Hypoglycemia and hyperinsulinism. Ann. Int. Med., 1934, 7, 1013.

24. Wauchope, G. M., Critical review: Hypoglycemia. Quart. J. Med., 1933, 2, 117.

25. Whipple, A. O., and Frantz, V. K., Adenoma of islet cells with hyperinsulinism. A review. Ann. Surg., 1935, 101, 1299.

26. Wilder, R. M., Allan, F. N., Power, M. H., and Robertson, H. E., Carcinoma of the islands of the pancreas. Hyperinsulinism and hypoglycemia. J. A. M. A., 1927, 89, 348. 